\title{
Performance of bovine genital campylobacteriosis diagnostic tests in bulls from Uruguay: a Bayesian latent class model approach
}

\author{
America Mederos $^{1}\left(\mathbb{0} \cdot\right.$. Denise Galarraga ${ }^{2} \cdot$ Linda van der Graaf-van Bloois $^{3} \cdot$ Sébastien Buczinski $^{4}$
}

Received: 19 July 2021 / Accepted: 16 December 2021 / Published online: 30 December 2021

(C) The Author(s), under exclusive licence to Springer Nature B.V. 2021

\begin{abstract}
The sensitivity (Se) and specificity ( $\mathrm{Sp}$ ) of three diagnostic tests for the detection of Campylobacter fetus venerealis (Cfv) using field samples were estimated using a Bayesian latent class model (BLCM), accounting for the absence of a gold standard. The tests included in this study were direct immunofluorescence antibody test (IFAT), polymerase chain reaction (PCR), and real-time PCR (RT-PCR). Twelve farms from two different populations were selected and bull prepuce samples were collected. The IFAT was performed according to the OIE Manual. The conventional PCR was performed as multiplex, targeting the gene $n a h E$ for $C$. fetus species identification and insertion element ISCfel for Cfv identification. The RT-PCR was performed as uniplex: one targeting the gene $n a h E$ for C. fetus and the other targeting the insertion ISCfel (ISC2) for Cfv. Results from the BLCM showed a median Se of 11.7\% (Bayesian credibility interval (BCI): 1.93-29.79\%), 53.7\% (BCI: 23.1-95.0\%), and 36.1\% (BCI: 14.5-71.7\%) for IFAT, PCR, and RT-PCR respectively. The Sp were 94.5\% (BCI: 90.1-97.9\%), 97.0\% (BCI: 92.9-99.3\%), and 98.4\% (BCI: 95.3-99.7\%) for IFAT, PCR, and RT-PCR respectively. The correlation between PCR and RT-PCR was positive and low in samples from both sampled population (0.63\% vs $8.47 \%$ ). These results suggest that diagnostic sensitivity of the studied tests is lower using field samples than using pure Cfv strains.
\end{abstract}

Keywords Beef cattle $\cdot$ Campylobacter fetus subspecies venerealis $\cdot$ Field samples $\cdot$ Latent class model

\section{Introduction}

Bovine genital campylobacteriosis (BGC) is a venereal disease affecting cattle herds. The causal agent is Campylobacter fetus (C. fetus) subspecies venerealis ( $\mathrm{Cfv})$. The main clinical sign of BGC is infertility, decreased pregnancy

America Mederos and Sébastien Buczinski contributed equally to this work.

America Mederos

amederos@inia.org.uy

1 Instituto Nacional de Investigación Agropecuaria (INIA), Programa Nacional Producción de Carne y Lana, Ruta 5 Km 386, Tacuarembó 45000, Uruguay

2 Private Diagnostic Laboratory, Tacuarembo, Uruguay

3 Department of Infectious Diseases and Immunology, Faculty of Veterinary Medicine, Utrecht University, Utrecht, The Netherlands

4 Faculté de Médecine Vétérinaire, Centre d'Expertise Et de Recherche Clinique en Santé Et Bien-Être Animal, Université de Montréal, Département des sciences cliniques, St-Hyacinthe, Canada rates due to early embryonic death, and occasional abortions resulting in economic losses (Michi et al. 2016). In South America, BGC has been reported in Argentina, Brazil, Paraguay, and Uruguay (Campero 2000a; Foscolo et al. 2005; Repisso et al. 2005). Studies conducted in Argentina reported that the prevalence of $\mathrm{Cfv}$ at the farm level ranged from 9.8 to $15.3 \%$, while at the animal level the prevalence of infected bulls ranged from 1 to 5\% (Campero 2000a, b; Campero and Martínez 2010). In Uruguay, a survey conducted by Repisso et al. (2005) reported $37 \%$ and $28 \%$ C. fetus sp. prevalence for beef herds and bulls respectively.

The diagnosis of BGC is by culture C. fetus isolates from preputial scrapings, cervical mucus or aborted fetus, and identification of the subspecies venerealis. The culture method is considered the golden standard and the prescribed diagnostic test for international trade (OIE 2017). However, there are many challenges to isolate $\mathrm{Cfv}$ from preputial samples. The micro-organism is slow-growing and requires strict micro-aerophilic conditions for growth and survival and lack sensitivity to detect infected bulls (García-Guerra et al. 2014). The direct immunofluorescent antibodies (IFAT) test is routinely applied, although it does not discriminate 
between subspecies venerealis and subspecies fetus. More recently, molecular tests have been developed as a promising fast and economic diagnostic tool for BGC detection, and $C$. fetus subspecies identification. At present, various PCR protocols are available in the published literature; some are targeting species $C$. fetus while others aim to differentiate subspecies Cfv and Cff (Abril et al. 2007; Hum et al. 1997; Tu et al. 2005; Wang et al. 2002). However, most of these published PCR protocols lack specificity or sensitivity to reliable classify $C$. fetus subspecies (van de Graaf-van Bloois et al. 2013).

In the absence of an available golden standard test, it is difficult to determine unbiased estimates of new test's accuracy if not accounting for reference standard test imperfection. Bayesian latent class methods (BLCMs) are useful to account for imperfect sensitivity and specificity of the reference standard tests. The BLCM approach is also a useful method since it incorporates some prior knowledge in the model that will therefore be updated with the new data that have been collected (McDonald and Hodgson 2018).

The objective of this study was to evaluate the accuracy of three diagnostic tests (IFAT, conventional PCR, and RT$\mathrm{PCR}$ ) for the detection of $C$. fetus venerealis (Cfv) in field samples from beef bulls obtained from two different populations. We hypothesize that these tests have limited sensitivity in the day-to-day diagnosis of the disease BGC. To fulfill our objective, we developed a Bayesian LCM accounting for the absence of the gold standard test. This manuscript was elaborated following the Standards for the Reporting of Diagnostic accuracy studies that use Bayesian Latent Class Models (Kostoulas et al. 2017).

\section{Materials and methods}

\section{Study population}

A prospective study was designed and conducted between August 2014 and September 2016 in the Northern part of Uruguay. The samplings were conducted at two levels. The first was at the farm level and the second at the animal level. At the farm level, two populations of beef herds from extensive production systems were purposively selected based on relatively low $(<70 \%)$ or relatively high $(>85 \%)$ reproductive index (which positively correlates with pregnancy and calving rates), and history of absence or presence of BGC prior to the enrollment for the study. The criteria to categorize a farm having a low or high reproduction index were based on the Uruguayan National Livestock Registry (DIEA 2014) reporting an average pregnancy rate range between 65 and $76 \%$ for beef cattle during the last past 10 years. Population 1 (Pop 1) consisted of six farms with high pregnancy rate $(>80 \%)$ and a negative diagnosis of BGC using culture (Harwood et al. 2009; OIE 2017) and PCR (Abril et al. 2007; Hum et al. 2009). Population 2 (Pop 2) consisted of six farms with low pregnancy rates $(<70 \%)$ and high $\mathrm{Cfv}$ prevalence $(>10 \%)$ in bulls at the beginning of the study.

Finally, at each farm, all bulls 2 years old and older were sampled using a bull scraping device (Tedesco et al. 1977). The bull samplings were performed before the breeding season, when the reproductive sound examination was performed and if the farmer agrees, 3 samplings per bull were conducted (10 to 15 days between each sampling). The samples were taken by veterinary practitioners following a specific protocol for ensuring sample quality. The research protocol was approved by the INIA ethics committee with the number 2015.41. Briefly, the scraping device was washed in 5-ml sterile PBS and after resting for $20 \mathrm{~min}$, two 1-ml aliquots were taken from the supernatant: one for DNA extraction and other for IFAT. One drop of $10 \%$ formalin was added to the IFAT aliquot.

\section{Laboratory tests}

The IFAT was performed as described in the OIE manual (2017) and it is the routine diagnostic test for Cfv used in Uruguay.

For the molecular tests, DNA was extracted using a commercial kit MagMax ${ }^{\mathrm{TM}}$ Pathogen RNA/DNA Kit (Applied Biosystems) designed for complex veterinary samples. The molecular test selection was based on having high sensitivity (Se) and specificity (Sp) according to published results.

The setup and in-house validation of the molecular tests were performed using a set of reference strains and field isolates from aborted fetuses or bulls detected positive by the bacteriological culture at the Ministry of Agriculture Diagnostic Laboratory (DILAVE) in Uruguay. The reference strains provided by the Campylobacter reference laboratory were classified using MLST and the local strains were classified by phenotypical methods. Additionally, for RT-PCR, the cutoff for field samples was determined using samples from a population of negative bulls from free farms and samples from positive bulls that were considered Cfv-positive by culture method.

The conventional PCR was performed as multiplex according to Abril et al. (2007) and modified by van derGraaf et al. (2013), targeting the gene nahE for C. fetus species identification $(\mathrm{Se}=100 \%$ and $\mathrm{Sp}=100 \%)$ and insertion element ISC $f e 1$ for $\mathrm{Cfv}$ identification $(\mathrm{Se}=95 \%$ and $\mathrm{Sp}=100 \%$ using DNA extracted from Campylobacter strains).

The RT-PCR was performed following the protocols described by van de Graaf-van Bloois et al. (2013) with modification as uniplex for field samples, one reaction targeting the gene $n a h E$ specific for $C$. fetus, and other separate reaction targeting the insertion ISC $f e l$ (ISC2) for $\mathrm{Cfv}$ 
( $\mathrm{Se}=100 \%$ and $\mathrm{Sp}=98 \%$ for bacteriological cultures). When processing the field samples, the laboratory personnel were blind to the farm status.

\section{Definition of test positivity classification}

For IFAT, a sample that presented at least one fluorescent organism showing typical morphology of $C$. fetus was considered positive.

The cutoff chosen to define a RT-PCR-positive result was a cycle threshold of $(\mathrm{Ct}) \leq 32$, corresponding to a detection limit of $2 \times 10^{+3} / \mu$ l for field samples. For conventional PCR, amplicons of $256 \mathrm{bp}$ were considered specific for the target pathogen $\mathrm{Cfv}$ and $80 \mathrm{bp}$ for $\mathrm{Cf}$. A positive $\mathrm{Cfv}$ result was defined when amplicons of $256 \mathrm{bp}$ and $80 \mathrm{bp}$ were obtained.

The data was included in the analysis if they have complete results for the three studied tests: direct immunofluorescence antibody test (IFAT), conventional polymerase chain reaction (PCR), and quantitative real-time PCR (RT-PCR). The Cohen's kappa test was used to estimate the agreement between tests using STATA/IC 16.1 (2019).

\section{Statistical analysis}

The target condition was an infection of the bull by Cfv. This status was defined as latent since none of the diagnostic tests used could be considered a gold standard test.

\section{Latent class model}

We used a two-population and three-test latent class model approach. The two populations were a priori considered having different prevalence of infection due to their different reproductive indices and previous $\mathrm{Cfv}$ farm status. For the molecular tests, a conditional dependence was a priori modeled since they were based on the same biological phenomenon (i.e., detection of DNA) and performed using the same samples.
The probabilities of each test result combination for the two populations were modeled using a multinomial distribution as previously mentioned (Branscum et al. 2005), based on test results probability patterns (immunofluorescence (IF), PCR, and RT-PCR) (Table 1).

The same approach was used for both populations assuming a different prevalence $(p)$ (low vs high prevalence population) as well as a constant sensitivity and specificity across low and high prevalence population.

The covariances between the two PCR tests were modeled as previously described (Dendukuri and Joseph 2001). The covariance among infected bulls (covDp) and non-infected bulls (covDn) was expressed as uniform distributions with specific bounds as follows:

$\operatorname{covDp} \sim$ dUniform $(0, \min (\operatorname{SePCR}$, SeRTPCR $)$ SePCR*SeRTPCR).

covDn $\sim$ dUniform $(0, \min ($ SpPCR, SpRTPCR $)-$ SpPCR*SpRTPCR).

\section{Prior specification}

Three experts were questioned a priori on the expected prevalence of infection in the two different populations. Beta distributions were obtained from best guesses and values, and the experts were $95 \%$ sure that the true value was below, using the PriorGen package from R (Kostoulas 2018). These priors were used in the main model (Model 1) and the best guess estimate of prevalence in the low risk herds was $10 \%$, being $95 \%$ sure that the true value was below $20 \%$ (Beta $(3.09,27.79))$. For the high-risk population, the best guess estimate was $40 \%$ being $95 \%$ sure it was lower than $70 \%$ (Beta $(2.84,4.25))$.

Some prior information was also available in the literature on the performance of the tests to detect $\mathrm{Cfv}$ using field samples (Se/Sp for IFAT and Sp for PCR and RT-PCR) (GarcíaGuerra et al. 2014). The SeIF (IFAT) best guess was 70\%, being $95 \%$ sure it was more than $10 \%$ (Beta $(1.38,1.16))$, the

Table 1 Description of the probabilities of the three test results in two populations

\begin{tabular}{|c|c|}
\hline Probability of specific test results & Full probability according to the three tests accuracy \\
\hline $\mathrm{P}(\mathrm{IF}+, \mathrm{PCR}+, \mathrm{RTPCR}+)=$ & $\mathrm{p}^{*} \operatorname{SeIF}^{*}(\operatorname{SePCR} * \operatorname{SeRTPCR}+\operatorname{covDp})+(1-\mathrm{p}) *(1-\operatorname{SpIF})^{*}((1-\operatorname{SpPCR}) *(1-\operatorname{SpRTPCR})+\operatorname{covDn})$ \\
\hline $\mathrm{P}(\mathrm{IF}+, \mathrm{PCR}+, \mathrm{RTPCR}-)$ & $\mathrm{p}^{*} \operatorname{SeIF}^{*}(\operatorname{SePCR} *[1-\operatorname{SeRTPCR}]-\operatorname{covDp})+(1-\mathrm{p}) *(1-\mathrm{SpIF})^{*}((1-\mathrm{SpPCR}) * \operatorname{SpRTPCR}-\operatorname{covDn})$ \\
\hline $\mathrm{P}(\mathrm{IF}+, \mathrm{PCR}-, \mathrm{RTPCR}+)$ & $\mathrm{p}^{*} \operatorname{SeIF}^{*}\left((1-\operatorname{SePCR})^{*} \operatorname{SeRTPCR}-\operatorname{covDp}\right)+(1-\mathrm{p})^{*}(1-\mathrm{SpIF})^{*}(\operatorname{SpPCR} *(1-\operatorname{SpRTPCR})-\operatorname{covDn})$ \\
\hline $\mathrm{P}(\mathrm{IF}+, \mathrm{PCR}-, \mathrm{RTPCR}-)$ & $\mathrm{p}^{*} \operatorname{SeIF}^{*}((1-\operatorname{SePCR}) *(1-\operatorname{SeRTPCR})+\operatorname{covDp})+(1-\mathrm{p}) *(1-\mathrm{SpIF}) *(\operatorname{SpPCR} * \operatorname{SpRTPCR}+\operatorname{covDn})$ \\
\hline $\mathrm{P}(\mathrm{IF}-, \mathrm{PCR}+, \mathrm{RTPCR}+)$ & $\mathrm{p}^{*}(1-\mathrm{SeIF}) *(\operatorname{SePCR} * \operatorname{SeRTPCR}+\operatorname{covDp})+(1-\mathrm{p}) * \operatorname{SpIF}^{*}((1-\operatorname{SpPCR}) *(1-\operatorname{SpRTPCR})+\operatorname{covDn})$ \\
\hline $\mathrm{P}(\mathrm{IF}-, \mathrm{PCR}+, \mathrm{RTPCR}-)$ & $\mathrm{p}^{*}(1-\mathrm{SeIF}) *(\operatorname{SePCR} *(1-\operatorname{SeRTPCR})-\operatorname{covDp})+(1-\mathrm{p}) * \operatorname{SpIF} *((1-\operatorname{SpPCR}) * \operatorname{SpRTPCR}-\operatorname{covDn})$ \\
\hline $\mathrm{P}(\mathrm{IF}-, \mathrm{PCR}-, \mathrm{RTPCR}+)$ & $\mathrm{p}^{*}(1-\mathrm{SeIF}) *((1-\mathrm{SePCR}) * \operatorname{SeRTPCR}-\operatorname{covDp})+(1-\mathrm{p}) * \operatorname{SpIF} *(\operatorname{SpPCR} *(1-\operatorname{SpRTPCR})-\operatorname{covDn})$ \\
\hline $\mathrm{P}(\mathrm{IF}-, \mathrm{PCR}-, \mathrm{RTPCR}-)$ & $\mathrm{p}^{*}(1-\mathrm{SeIF}) *((1-\mathrm{SePCR}) *(1-\mathrm{SeRTPCR})+\operatorname{covDp})+(1-\mathrm{p})^{*} \operatorname{SpIF}^{*}(\operatorname{SpPCR} * \operatorname{SpRTPCR}+\operatorname{covDn})$ \\
\hline
\end{tabular}

$P$ probability, $I F$ immunofluorescence antibody test, $P C R$ polymerase chain reaction, $R T-P C R$ real-time PCR, $S e$ sensitivity, $S p$ specificity, $\operatorname{cov} D p$ covariance among infected bulls, covDn covariance among non-infected bulls 
best guess for SpIFAT was $80 \%$, being 95\% confident than it was higher than $50 \%$ (Beta $(6.55,2.64))$. Since PCR and RT-PCR tests were anticipated to be highly specific, the best guesses for SpPCR and SpRT-PCR were 95\% being 95\% sure it was higher than $80 \%$ (Beta $(21.2,2.06)$ ).

\section{Model implementation}

All the models were implemented in OpenBUGS (Lunn et al. 2009) using the R interface R2WinBUGS (Sturtz et al. 2005). Three chains with difference in its starting points were run for all modeling approaches. An initial burn-in of 50,000 iterations was a priori defined to ensure convergence of chains for posterior sampling. Thinning was adapted when needed for limiting autocorrelation between iterations when observed. The posteriors were derived from a total of 50.000 iterations. The deviance information criterion (DIC) was calculated as a general indicator of model fit. Convergence of the chains was visually checked and assessed using the Gelman Rubin diagnostic.

\section{Sensitivity analyses}

To determine the impact of the prior on the posterior densities, two additional models were ran using weakly informative priors on the prevalence or for the tests $\mathrm{Se}$ and $\mathrm{Sp}$ (Depaoli et al. 2020; Natesan Batley and Hedges 2021; Paradis et al. 2012). In model 2, we used relaxed estimates for the prevalence in the two populations. The same best guesses for both prevalences were used (10\% and $40 \%$ for populations 1 and 2 respectively) but with a larger spread around the best guess than in the initial model (upper bound to $50 \%$ for the low-risk population and lower bound of $10 \%$ for the higher risk population). The same priors as model 1 were used for all test sensitivities and specificities. Finally, in model 3, we used informative priors used in model 1 for the prevalence with all non-informative priors for test sensitivities and specificities (Beta $(1,1))$.

\section{Results}

The final database was obtained from 12 extensive beef farms and consisted of 156 and 111 bulls' samples for Pop 1 and Pop 2, respectively. The main breeds were British $(n=9)$ and Continental $(n=3)$ breed cattle.

The mean herd size was 493 breeding animals and varied from 140 to 1070 breeding cows and 3 to 35 bulls.

For Pop $1,3.03 \%, 1.5 \%$, and $0.0 \%$ of the samples were positive for IFAT, PCR, and RT-PCT, respectively, and for Pop 2, $10.0 \%, 20.6 \%$, and $12.4 \%$ of the samples were positive for IFAT, PCR, and RT-PCR, respectively. Table 2 presents the cross-classified data of the results for the three studied tests applied simultaneously to all samples, divided by population and sampled farms.

Results from the Cohen's kappa test demonstrated a moderate agreement between PCR and RT-PCR (kappa $=0.60$;

farms from two populations defined as low prevalence (population 1) and high prevalence (population 2)

2 Cross-tabulated results of immunofluorescence antibo ies (IFAT), PCR, and real-time PCR (RT-PCR) for the detection of Campylobacter fetus venerealis, performed on 267 bulls from 12

\begin{tabular}{|c|c|c|c|c|c|c|c|c|c|}
\hline Farm no & $\begin{array}{l}\text { IFAT +, } \\
\text { PCR +, RT- } \\
\text { PCR }+\end{array}$ & $\begin{array}{l}\text { IFAT+, } \\
\text { PCR +, RT- } \\
\text { PCR- }\end{array}$ & $\begin{array}{l}\text { IFAT +, } \\
\text { PCR-, RT- } \\
\text { PCR + }\end{array}$ & $\begin{array}{l}\text { IFAT +, } \\
\text { PCR-, RT- } \\
\text { PCR- }\end{array}$ & $\begin{array}{l}\text { IFAT-, } \\
\text { PCR +, RT- } \\
\text { PCR }+\end{array}$ & $\begin{array}{l}\text { IFAT-, } \\
\text { PCR +, RT- } \\
\text { PCR- }\end{array}$ & $\begin{array}{l}\text { IFAT-, PCR-, } \\
\text { RT-PCR + }\end{array}$ & $\begin{array}{l}\text { IFAT-, } \\
\text { PCR-, RT- } \\
\text { PCR- }\end{array}$ & Total \\
\hline \multicolumn{10}{|c|}{ Population 1} \\
\hline 4 & 0 & 0 & 0 & 0 & 0 & 2 & 0 & 2 & 4 \\
\hline 8 & 0 & 0 & 0 & 0 & 0 & 0 & 0 & 3 & 3 \\
\hline 9 & 0 & 0 & 0 & 3 & 0 & 0 & 0 & 81 & 84 \\
\hline 10 & 0 & 0 & 0 & 0 & 0 & 0 & 0 & 12 & 12 \\
\hline 11 & 0 & 0 & 0 & 0 & 0 & 0 & 0 & 4 & 4 \\
\hline 12 & 0 & 0 & 0 & 0 & 0 & 0 & 0 & 9 & 9 \\
\hline Total & 0 & 0 & 0 & 3 & 0 & 2 & o & 111 & 116 \\
\hline \multicolumn{10}{|c|}{ Population 2} \\
\hline 1 & 0 & 1 & 0 & 0 & 1 & 5 & 1 & 10 & 18 \\
\hline 2 & 0 & 0 & 0 & 0 & 0 & 0 & 0 & 4 & 4 \\
\hline 3 & 0 & 0 & 0 & 0 & 0 & 1 & 1 & 4 & 6 \\
\hline 5 & 0 & 0 & 0 & 0 & 0 & 1 & 0 & 13 & 14 \\
\hline 6 & 0 & 0 & 0 & 6 & 9 & 0 & 0 & 34 & 49 \\
\hline 7 & 0 & 0 & 0 & 1 & 0 & 0 & 0 & 0 & 1 \\
\hline Total & 0 & 1 & 0 & 7 & 10 & 7 & 2 & 65 & 92 \\
\hline
\end{tabular}


$p=0.000)$. There was not agreement between IFAT and the molecular tests.

\section{Main informative model results}

The beta prior's distribution for $\mathrm{Se}, \mathrm{Sp}$, and prevalence for the models are presented above. The mean estimates for sensitivity and specificity along with $95 \%$ credible interval (BCI) for IFAT, PCR, and RT-PCR for the three models are given in Table 3 and Fig. 1. A small positive correlation between truly non-infected bulls (covDn) was observed for PCR and RT-PCR tests, and no specific covariance could be detected among infected bulls between the same two tests since the $95 \%$ BCI included zero.

\section{Sensitivity analysis}

Table 3 presents the results for the estimated parameters for non-informative priors for prevalence and non-informative for prevalence and $\mathrm{Se}$ and $\mathrm{Sp}$, respectively. The overlaying posterior densities of accuracy estimates of model 1 vs model 2 and model 1 vs model 3 are presented in Fig. 2A and $\mathrm{B}$ respectively.

\section{Discussion and conclusion}

In this work, we studied the sensitivity and specificity of diagnostic tests for $\mathrm{Cfv}$ using field samples. Due to the absence of a highly sensitive gold standard, we applied a Bayesian latent class model to analyze the Se and Sp of the studied tests. The scope of the study was not to model posterior parameters for prevalence. The results presented above indicated low sensitivity of the tests when applied to samples obtained directly from bulls.

Results from all models estimated that RT-PCR has higher specificity to detect non-infected bulls with Cfv; however, conventional PCR has higher Se to detect Cfv from field samples. Our posterior findings were under the a priori classification of the two populations.

The sensitivity analysis did not reveal large differences between the models since the mean estimates of the midinformative models were included in the $95 \%$ BCI of the main model. The DIC difference between the models was lower than the 3-5 range which is generally considered a minimal difference to determine if a model is better than another (Adrion and Mansmann 2012).

Table 3 Prior densities and mean posterior estimates (95\% Bayesian credibility interval) of sensitivity (Se) and specificity (SP) of IFAT, PCR, and RT-PCR for Campylobacter fetus venerealis detection in bulls. Informative model for two population and three tests

\begin{tabular}{|c|c|c|c|c|c|c|}
\hline \multirow[t]{3}{*}{ Parameter } & \multicolumn{6}{|l|}{ Models } \\
\hline & \multicolumn{2}{|c|}{$\begin{array}{l}\text { Main model: informative model } \\
(\text { Model 1) }\end{array}$} & \multicolumn{2}{|c|}{$\begin{array}{l}\text { Mid-informative for prevalence } \\
(\text { Model 2) }\end{array}$} & \multicolumn{2}{|c|}{$\begin{array}{l}\text { Non-informative for test accuracy } \\
(\text { Model 3) }\end{array}$} \\
\hline & Prior densities & Posterior estimates $^{\mathrm{d}}$ & Prior densities ${ }^{\mathrm{d}}$ & Posterior estimates $^{\mathrm{d}}$ & Prior densities & Posterior estimates $^{\mathrm{d}}$ \\
\hline Se-IFAT $(\%)$ & $\beta(1.38,1.16)$ & $12.8(1.93-29.79)$ & $\beta(1.38,1.16)$ & $13.0(1.59-31.78)$ & $\beta(1,1)$ & $112.0(1.3-28.3)$ \\
\hline Se-PCR (\%) & $\beta(1,1)$ & $56.2(23.17-95.09)$ & $\beta(1,1)$ & $68.0(29.0-97.3)$ & $\beta(1,1)$ & $53.6(22.6-93.5)$ \\
\hline Se-RT-PCR (\%) & $\beta(1,1)$ & $38.7(14.54-71.71)$ & $\beta(1,1)$ & $49.0(19.3-82.4)$ & $\beta(1)$ & $36.6(14.2-69.8)$ \\
\hline Sp-IFAT (\%) & $\beta(1,1)$ & 94.5 (90.18-97.94) & $\beta(1,1)$ & $94.2(90.0-97.4)$ & $\beta(1,1)$ & $95.4(90.0-99.0)$ \\
\hline Sp-PCR (\%) & $\beta(21.2,2.06)$ & $97.0(92.96-99.38)$ & $\beta(21.2,2.06)$ & $96.4(92.6-98.9)$ & $\beta(1,1)$ & $97.6(93.5-99.8)$ \\
\hline Sp-RT-PCR (\%) & $\beta(21.2,2.06)$ & $98.2(95.31-99.76)$ & $\beta(21.2,2.06)$ & $98.3(95.5-99.7)$ & $\beta(1,1)$ & $98.9(96.2-99.9)$ \\
\hline Pi 1 (\%) & $\beta(3.09,27.79)$ & $3.9(0.78-9.82)$ & $\beta(1,1)$ & $0.3(0.00-2.6)$ & $\beta(3.09,27.79)$ & $4.1(0.84-10.4)$ \\
\hline Pi $2(\%)$ & $\beta(2.84,4.25)$ & 34.7 (14.94-66.88) & $\beta(1,1)$ & $27.3(12.1-58.0)$ & $\beta(2.84,4.25)$ & $37.7(16.3-70.0)$ \\
\hline CovDp $^{\mathrm{e}}$ & - & $0.077(-.0373-0.1678)$ & - & $0.054(-0.05-0.16)$ & - & $0.079(-.03-0.17)$ \\
\hline $\operatorname{CovDn}^{\mathrm{f}}$ & - & $0.0087(0.00-3,07)$ & - & $0.008(0.00-0.029)$ & - & $0.004(0.00-0.022)$ \\
\hline DIC & - & 40.3 & - & 37.6 & - & 38.0 \\
\hline
\end{tabular}

IFAT immunofluorescence antibodies, $P C R$ polymerase chain reaction, $R T$ - $P C R$ real-time PCR, DIC deviance information criterion

${ }^{\text {a Priors: }}$ P1 (prevalence) mean $=10.0,95 \mathrm{th}=20.0 ;$ P2 mean $=40.0,95 \mathrm{th}=70.0 ;$ SeIFAT mean $=70.0,95 \mathrm{th}=>10.0 ;$ SpIFAT $=80.0$; 95th $=>50.0 ;$ SpPCR and RT-PCR mean $=95.0 ; 95$ th $=>80.0$

${ }^{\text {bPrior: }}$ P1 (prevalence) mean $=10.0,95 \mathrm{th}=50.0 ;$ P2 mean $=40.0,2.5$ th $=10.0 ;$ SeIFAT mean $=70.0,95 \mathrm{th}=>10.0 ;$ SpIFAT $=80.0$; 95th $=>50.0 ;$ SpPCR and RT-PCR mean $=95.0 ; 95$ th $=>80.0$

${ }^{\mathrm{c}}$ Priors: $\mathrm{P} 1$ (prevalence) mean $=10.0,95 \mathrm{th}=20.0 ; \mathrm{P} 2$ mean $=40.0,95 \mathrm{th}=70.0$

${ }^{\mathrm{d}}$ Posteriors estimates are expressed as percentage for all variables but covDp and covDn, along with 95\% Bayesian credibility intervals

${ }^{\mathrm{e}}$ Covariance among positive population $=\operatorname{covDp} \sim \mathrm{dUniform}(0, \min (\mathrm{SePCR}, \mathrm{SeRTPCR})-\mathrm{SePCR} * \mathrm{SeRTPCR})$

${ }^{\mathrm{f}}$ Covariance among negative population $=\operatorname{covDn} \sim \mathrm{dUniform}(0, \min (\mathrm{SpPCR}, \mathrm{SpRTPCR})-\mathrm{SpPCR} * \mathrm{SpRTPCR})$ 


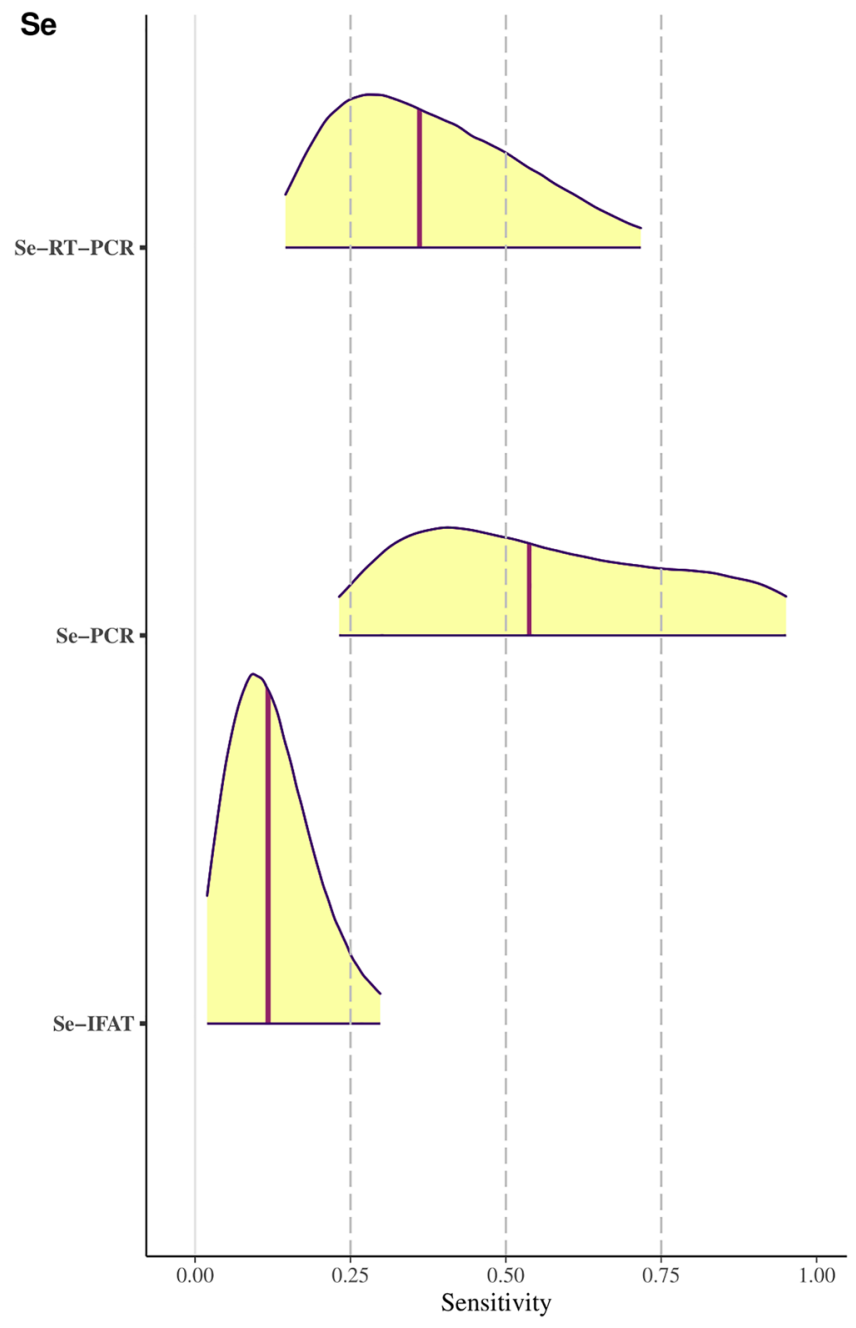

Fig. 1 Presentation of the 95\% percent credible intervals of posterior densities of test accuracies for the detection of bovine genital campylobacteriosis infection in Uruguayan bulls. The shaded area

Interestingly, despite the convergence of the models, the sensitivity of PCR tests had a wide posterior distribution. Therefore, a wide uncertainty was observed for this parameter. However, both PCR and RT-PCR tests had a higher sensitivity than the IFAT test.

When studying diagnostic Se and Sp, we follow the assumption that these parameters do not dependent on disease prevalence. However, some authors in the medical field suggest that test accuracy is dependent on population characteristics which also include prevalence characteristics (Leeflang et al. 2013). A lower prevalence means a narrower spectrum of disease manifestation which may impact the accuracy of the diagnostic tests employed.

The test accuracy may also depend on possible unmeasured covariates among sampled populations as extensively discussed (Wang et al. 2017). Unfortunately, due to the relatively low number of infected bulls in Pop 2, and limited

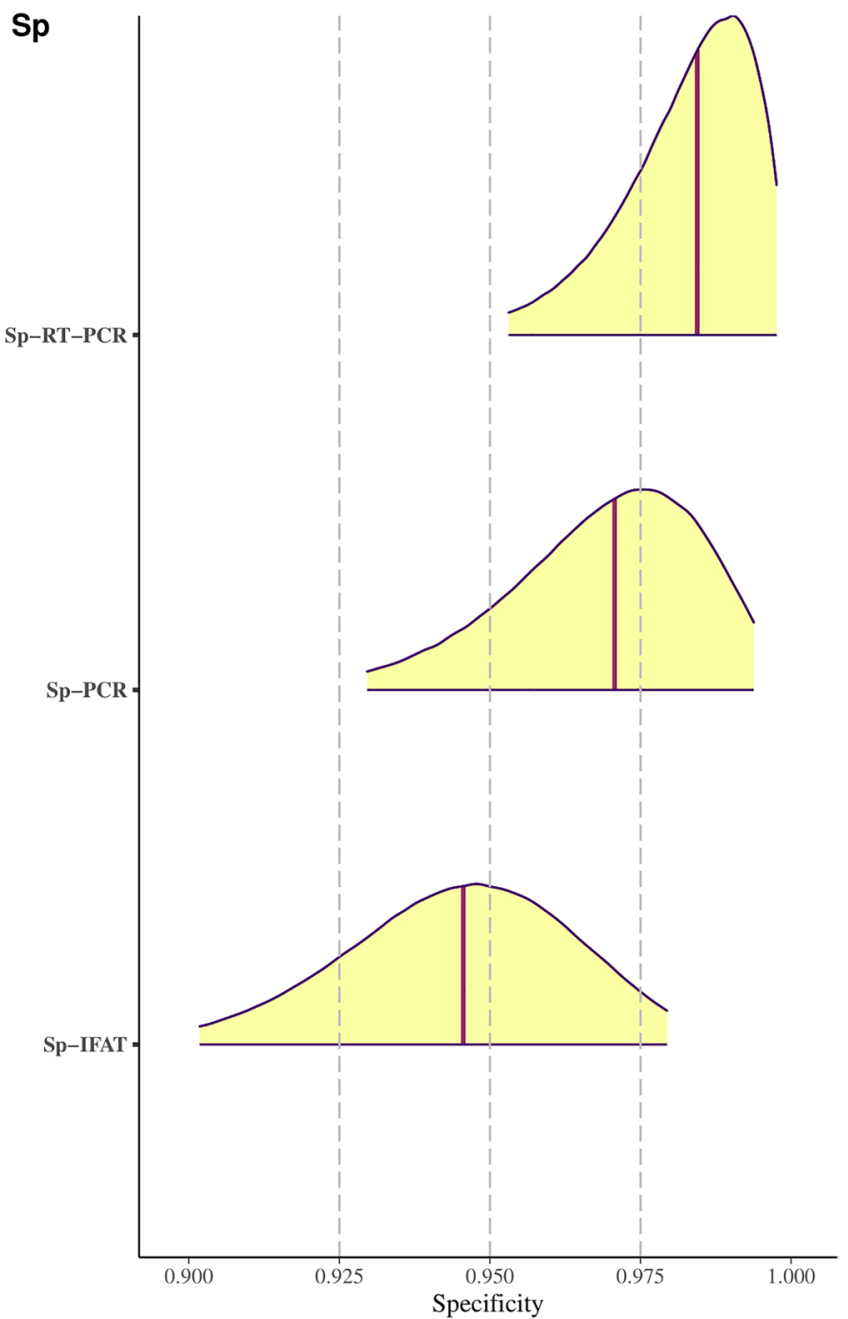

represents the $95 \%$ Bayesian credible intervals. The median estimate is also indicated as a thick line for the tests sensitivities (A) and specificities $(\mathbf{B})$

clinical information on the samples used, we could not explore this hypothesis. We cannot rule out that a specific unmeasured covariate could interfere with PCR sensitivity in our study. This could be a possible explanation of the wide credible interval observed for this parameter.

As described above, we have selected two independent population of herds, one having a high and other having a low probability of being infected. However, in the infected herds, not all the bulls are positive since they became more susceptible with the age. This aspect introduces complexity to find populations for estimating the diagnostic sensitivity using imperfect tests classification.

The work conducted by García-Guerra et al. (2014) used bull field samples to study several $\mathrm{Cfv}$ diagnostic test performance. Their results reported a Sp for RT-PCR lower than our study ( $85.0 \%$ vs $98.4 \%$ ), but higher Se than our study ( $85.4 \%$ vs $36.1 \%$ ) using artificially challenged 

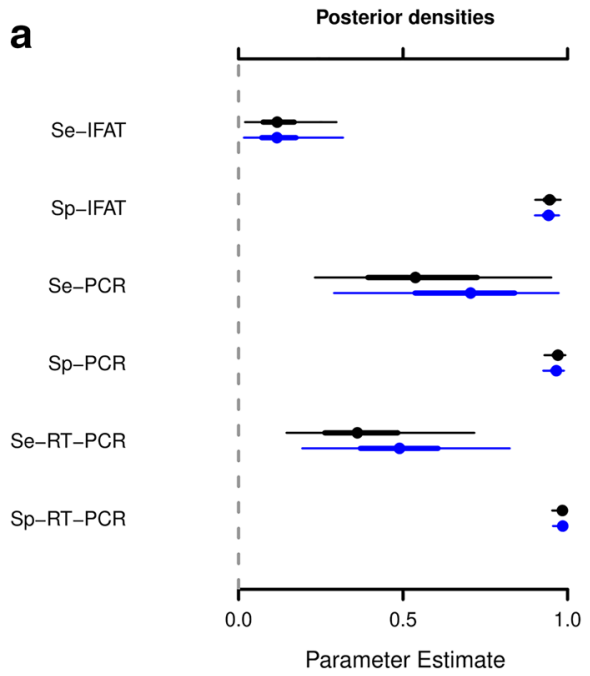

Fig. 2 A, B Overlaying of median estimates, 50 and 95\% Bayesian credible intervals of the main model and models used for sensitivity analysis of test accuracies for the detection of bovine genital campylobacteriosis infection in Uruguayan bulls. The estimates interval width for $\mathrm{Se} / \mathrm{Sp}$ of the 3 tests used for detection of bovine genital

bulls $(n=13)$ that were repeatedly sampled. Therefore, this result could not be extrapolated to field situations where naturally disease occurs, and particularly with lower bacteria load difficult to diagnose.

A systematic review-meta-analysis conducted by us (data unpublished) identified four publications using IFAT to detect $\mathrm{Cfv}$ on field samples using bacteriological culture as reference test. From these studies, the estimated mean sensitivity was $77.8 \%$ (range: $43.7-99.7 \%$ ), and mean specificity was $84.5 \%$ (range: $71.4-95.1 \%$ ) (Cipolla et al. 1994; García-Guerra et al. 2014; Rocha et al. 2009; Ruckerbauer et al. 1974). Two studies describing PCR as index test and bacteriological culture as reference standard presented a mean Se of $93.6 \%$ (range: $87.5-99.8 \%$ ) and mean Sp of $88.4 \%$ (range: 77.6-99.0\%) for PCR (Groff et al. 2010; Schmidt et al. 2010).

Another constraint that can affect the sensitivity of the diagnostic tests, particularly molecular ones, is that the field samples obtained from bull prepuce can be contaminated with dust, fecal material, and other microorganisms. Molecular tests are more efficient in detecting a low amount of the desired pathogens, although they are also very prone to inhibition by sample contaminants.

The results from our BLCM suggest the complexity of Cfv detection using field samples, mainly bull scrapes, and highlight the difficulties in defining appropriately the study populations for diagnostic test accuracy. Increasing the sample size could improve the results, although the number of bulls per farm is limited. Repeated sampling of

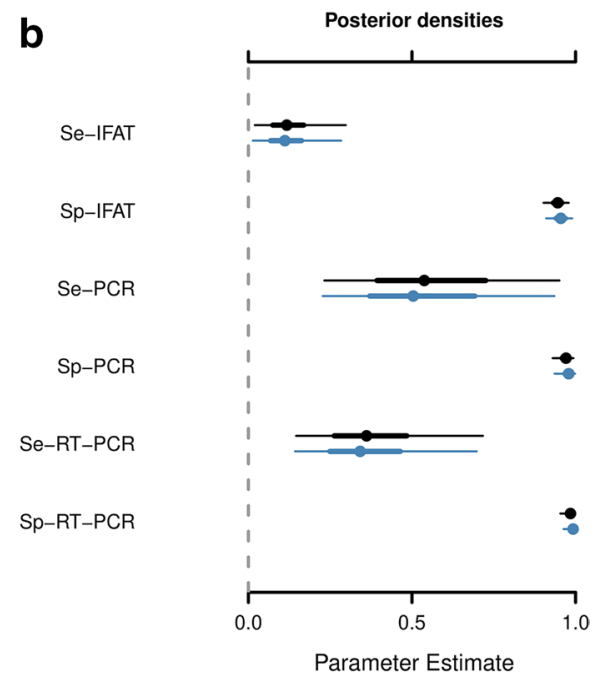

campylobacteriosis infection in Uruguayan bulls is represented in the upper line, versus model 2 estimates (lower line, panel A) and model 3 (lower line, panel B). The thick and thin line of the range indicate the $50^{\text {th }}$ and $95^{\text {th }}$ Bayesian credible interval range. The dot is indicating the median estimate. For model prior specification, see Table 2

the same bulls over a specific timeframe could increase the chances of finding evidence of infection, although it will add more complexity to the models due to dependence.

Latent class models allow estimating diagnostic test accuracy in the absence of a gold standard. Knowing the sensitivity and specificity of the tests could allow using more than one test in parallel (assuming conditional independence or accounting for dependence between the results) to increase Se, particularly in those herds where $\mathrm{Cfv}$ is suspected to be present.

Acknowledgements The authors thank the farm owners for collaborating in the project.

Funding This work was funded by Instituto Nacional de Investigación Agropecuaria (INIA) and Agencia Nacional de Investigación e Innovación (ANII) under project FSSA_X_2014_1_105894.

Data availability Data and codes for the models are available upon request.

Code availability All the models were implemented in OpenBUGS using the R interface R2WinBUGS.

\section{Declarations}

Ethical standards The study involved the use of client-owned animals and was restricted to bull preputial scrapings performed by veterinary practitioners during their general activity. The research protocol was approved by the INIA ethics committee with the number 2015.41 .

Conflict of interest The authors declare no competing interests. 


\section{References}

Abril, C., Vilei, E.M.; Brodard, I., Burnens, A., Frey, J., Miserez, R., 2007. Discovery of insertion element ISCfe1: a new tool for Campylobacter fetus subspecies differentiation. Clinical Microbiology and Infection, 13, 10, 993-1000

Adrion, C and Mansmann, U., 2012. Bayesian model selection techniques as decision support for shaping a statistical analysis plan of a clinical trial: An example from a vertigo phase III study with longitudinal count data as primary endpoint. BMC Medical Research Methodology; 12:137.

Anuario estadístico DIEA 2014. https://www.gub.uy/ministerio-ganad eria-agricultura-pesca/comunicacion/publicaciones/anuario-estad istico-diea-2014

Branscum,A.J.; Gardner, I.A.; Johnson, W.O., 2005. Estimation of diagnostic-test sensitivity and specificity through Bayesian modeling. Preventive Veterinary Medicine; 68 (2), 145-163.

Campero, C.M. and Martínez, A.,2010. Las enfermedades de transmisión sexual en los bovinos: su persistencia en los sistemas de cría. Jornadas de Actualización en Enfermedades de los Bovinos, Laboratorio Azul; Azul, 7- 8 de Mayo 2010.

Campero, C.M., 2000a. Las enfermedades reproductivas de los bovinos: ayer y hoy. Academia Nacional de Agronomía Veterinaria Anales; 53: 88-112.

Campero, C.M., 2000b. Causas frecuentes de aborto en Argentina. $5^{\circ}$ Congreso Argentino de Reproducción Animal; 1-12.

Cipolla, A. L., Casaro, A. P., Terzolo, H. R., Estela, E. S., Brooks, B. W., Garcia, M. M., 1994. Persistence of Campylobacter fetus subspecies venerealis in artificially infected heifers. Veterinary Record; 134, 628 .

Dendukuri, N. and Joseph, L., 2001. Bayesian approaches to modeling the conditional dependence between multiple diagnostic tests. Biometrics; 57(1):158-67.

Depaoli, S., Winter, S.D., Visser, M., 2020. The Importance of Prior Sensitivity Analysis in Bayesian Statistics: Demonstrations Using an Interactive Shiny App. Frontiers on Psychology. 24;11: 608045. https://doi.org/10.3389/fpsyg.2020.608045.

Foscolo, C.B., Pellegrin, A.O., Leite, R.C., Stynen, A.P.R., Lage, A.P., 2005. Vaccination of bulls against bovine genital campylobacteriosis: a therapeutic approach. Animal Reproduction; 2: 122-127.

García-Guerra, A., Chaban, B., Hill, J.E., Waldner, S. L., Hendrick, S.H., 2014. Clinical sensitivity and specificity of a real-time PCR Assay for Campylobacter Fetus subsp venerealis in preputial samples from bulls. American Journal of Veterinary Research; 75 (9), 851-60.

Groff, A. C. M., Kirinus J. K., Sá e Silva, M., Machado G., Costa M. M., Vargas A. P. C., 2010. Polymerase chain reaction for the diagnosis of bovine genital campylobacteriosis.Pesquisa Veterinaria Brasileira; 30- 12, 1031-1035.

Harwood, L.J., Thomann, A., Brodard, I., Makaya, P.V., Perreten, V., 2009. Campylobacter fetus subspecies venerealis transport medium for enrichment and PCR. Veterinary. Record; 165, 507-508.

Hum, S., Quinn, K., Brunner, J. On, S. L. W., 1997. Evaluation of a PCR assay for identification and differentiation of Campylobacter fetus subspecies. Australian Veterinary Journal; 75, 11,827-831.

Hum, S., Hornitzky, M., Berg., T., 2009. Bovine genital campylobacteriosis. Australia and New Zealand Standard Diagnostic Procedures; $1-19$.

Kostoulas, P, Nielsen, S.S., Branscum, A.J., Johnson, W.O., Dendukuri, N., Dhand, N.K., Toft, N., Gardner, I.A., 2017. STARD-BLCM: Standards for the Reporting of Diagnostic accuracy studies that use Bayesian Latent Class Models. Preventive Veterinary Medicine; 138, 37-47. https://doi.org/10.1016/j.prevetmed.2017.01. 006
Kostoulas P., 2018. https://CRAN.R-project.org/package=PriorGen Leeflang, M.M, Rutjes, A.W., Reitsma, J.B., Hooft, L., Bossuyt, P.M., 2013. Variation of a test's sensitivity and specificity with disease prevalence. Canadian Medical Association Journal;185(11): E537-E544. https://doi.org/10.1503/cmaj.121286.

Lunn, D., Spiegelhalter, D., Thomas, A. and Best, N., 2009. The BUGS project: Evolution, critique and future directions (with discussion), Statistics in Medicine; 28: 3049--3082.

McDonald, J.L. and Hodgson, D.J., 2018. Prior Precision, Prior Accuracy, and the Estimation of Disease Prevalence Using Imperfect Diagnostic Tests. Frontiers in Veterinary Science; 5:83. https://doi.org/10.3389/fvets.2018.00083. eCollection 2018 .

Michi, A. N., Favetto, P. H., Kastelic, J., Eduardo R. Cobo, E. R., 2016. A review of sexually transmitted bovine trichomoniasis and campylobacteriosis affecting cattle reproductive health. Theriogenology; 85, $781-791$.

Natesan Batley, P. and Hedges, L.V., 2021. Accurate models vs. accurate estimates: A simulation study of Bayesian single-case experimental designs. Behavior Research Methods 53,4: 1782-1798. https://doi.org/10.3758/s13428-020-01522-0

Office International des Epizooties (2017) Manual de la OIE sobre animales terrestres. Capítulo 2.4.4. Campylobacteriosis genital bovina. http://www.oie.int/fileadmin/Home/esp/Health_stand ards/tahm/2.04.04_Campilobact_bovina.pdf. Accessed: December 2018 .

Paradis, M.E., Haine, D., Gillespie, B., Oliver, S.P., Messier, S., Comeau, J., Scholl, D.T. 2012. Bayesian estimation of the diagnostic accuracy of a multiplex real-time PCR assay and bacteriological culture for 4 common bovine intramammary pathogens. Journal of Dairy Science. 95(11):6436-48. https://doi.org/10. 3168/jds.2012-5328.

Repisso, M.V., Gil, A., Bañales, P., D’Anatro, N., Fernandez, L., Guarino, H., Herrera, B., Nuñez, A., Olivera, M., Osawa, T., Silva, M., 2005. Prevalencia de las principales enfermedades infecciosas que afectan el comportamiento reproductivo en la ganadería de carne y caracterización de los establecimientos de cría del Uruguay. Veterinaria 2005, 40, 5-28.

Rocha, F. S., Jesus, V. L. T., Torres, H. M., Gomes, M. J. P., Figueiredo, M. J., Nascimento, E. R., Ferreira, T., Aquino, M. H. C., 2009. Campylobacter fetus and Tritrichomonas foetus investigation in prepucial mucous of bulls from Medio Paraiba/RJ Region, Brazil. Ciencia Rural; 39:5,1586-1589.

Ruckerbauer, G.M., Malkin K., Mitchell D., Boulanger P., 1974. Vibriosis: demonstration of Vibrio fetus and Vibrio bubulus organisms in preputial fluid by immunofluorescence and cultural techniques. Canadian Journal of Comparative Medicine; 38: 321-327

Schmidt, T., Venter, E. H., Picard, J. A., 2010. Evaluation of PCR assays for the detection of Campylobacter fetus in bovine preputial scrapings and the identification of subspecies in South African field isolates. Journal of the South African Veterinary Association; 81, 2: 87-92.

StataCorp. 2019. Stata: Release 16. Statistical Software. College Station, TX: StataCorp LLC.

Sturtz, S., Ligges, U., and Gelman, A., 2005. R2WinBUGS: A Package for Running WinBUGS from R. Journal of Statistical Software; 12(3), 1-16.

Tedesco, L.F., Errico, F., Del Baglivi, L.P., 1977. Comparison of three sampling methods for the diagnosis of bovine genital vibriosis in the bulls. Australian Veterinary Journal;53, 470-472.

Tu, Z.C., Eisner, W., Kreiswirth, B.N., Blaser, M.J., 2005. Genetic divergence of Campylobacter fetus strains of mammal and reptile origins. Journal of Clinical Microbiology; 43, 3334-3340.

van de Graaf-van Bloois, L., van Bergen, M.A.P., van der Wal, F.J., de Boer, A.G., Duim, B., Schmidt, T., Wagenaar, J.A., 2013. 
Evaluation of molecular assays for identification Campylobacter fetus species and subspecies development of a C. fetus specific real-time PCR assay. Journal of Microbiological Methods 2013; 95:93-97.

Wang, Z., Dendukuri, N., Zar, H.J., Joseph, L., 2017. Understanding the effects of conditional dependence in research studies involving imperfect diagnostic tests. Statistics in Medicine; 36(3):466-480. https://doi.org/10.1002/sim.7148.
Wang, G., Clark, C.G., Taylor, T.M., Pucknell, C., Barton, C., Price, L., Woodward, D.L., Rodgers, F.G., 2002. Colony multiplex PCR assay for identification and differentiation of Campylobacter jejuni, C. coli, C. lari, C. upsaliensis, and C. fetus subsp. fetus. Journal of Clinical Microbiology; 40, 4744-4747.

Publisher's note Springer Nature remains neutral with regard to jurisdictional claims in published maps and institutional affiliations. 